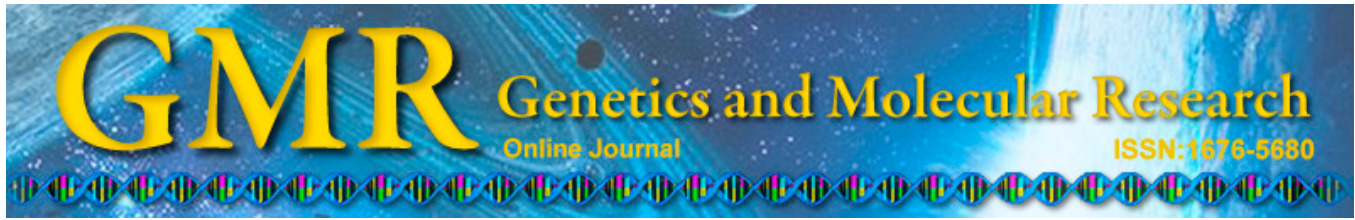

\title{
Detection of the genetic variation of polygalacturonase-inhibiting protein gene 2 in autotetraploid alfalfa (Medicago sativa) using an improved SSCP technique
}

\author{
Z. Gui ${ }^{1}$, H.Q. Liu ${ }^{1}$, Y. Wang ${ }^{2}$, Q.H. Yuan ${ }^{2}$, N. Xin ${ }^{1}$, X. Zhang ${ }^{1}$, X.L. Li ${ }^{2}$, \\ Y.S. Pi ${ }^{1}$ and J.M. Gao \\ ${ }^{1}$ Key Laboratory of Crop Genetics and Breeding, \\ Department of Agronomy, Tianjin Agricultural University, Tianjin, China \\ ${ }^{2}$ Institute of Animal Science, Chinese Academy of Agricultural Science, \\ Beijing, China \\ Corresponding author: J.M. Gao \\ E-mail: gao11799713@163.com
}

Genet. Mol. Res. 13 (4): 10184-10193 (2014)

Received January 6, 2014

Accepted March 28, 2014

Published December 4, 2014

DOI http://dx.doi.org/10.4238/2014.December.4.13

\begin{abstract}
In this study, 2 approaches were adopted to obtain good single-strand conformation polymorphism (SSCP) data for autotetraploid alfalfa; primers were added to PCR products, and fluorescent-labeled primers were utilized. PCR-SSCP conditions for a 331-bp fragment in the coding region of polygalacturonase-inhibiting protein gene 2 in alfalfa $(M S P G I P 2)$ were optimized, and the results showed that the best SSCP gel pattern could be obtained when the loading mixture was made by mixing $1 \mu \mathrm{L}$ PCR products, 0.2 to $0.8 \mu \mathrm{L}$ unlabeled primers $(50 \mu \mathrm{M})$ and 4 to $16 \mu \mathrm{L}$ loading buffer. Furthermore, the use of the fluorescent-labeled primers resulted in 2 separated electrophoresis images from 2 complementary single DNA strands, thus making the determination of alleles and idiotypes a relatively easy task. In addition, the results of sequencing prove that the determination
\end{abstract}


of alleles and idiotypes were accurate based on SSCP analysis. Finally, a total of 9 alleles with 18 SNP sites were identified for $M S P G I P 2$ in the alfalfa variety 'Algonquin'. In conclusion, $M S P G I P 2$ possessed great genetic variation, and the addition of primers to the PCR products in combination with the fluorescent labeling of primers could significantly improve the sensitivity and resolution of SSCP analysis. This technique could be used for genetic diversity detection and marker-assisted breeding of useful genes in autopolyploid species such as alfalfa.

Key words: Lucerne; Autopolyploid; Primer concentration; Single-strand conformation polymorphism; Fluorescent labeling; Sequence variation

\section{INTRODUCTION}

Single-stranded DNA (ssDNA) fragments have complex folding conformations. Such three-dimensional structures are sustained by intramolecular interactions represented by base pairing, and the mutation of a single or multiple bases will result in changes in conformation. ssDNA molecules with similar sizes but different conformations show different migration rates in nondenaturing polyacrylamide gel (PAGE) and, therefore, can be easily separated (Orita et al., 1989; Kusakabe et al., 1993). This analysis tool is known as single-strand conformation polymorphism (SSCP) analysis, which is featured by its simplicity, rapidity, and sensitivity. Its combined use with polymerase chain reaction (PCR) has extensive applications in the detection of DNA mutations (Ishikawa et al., 2002; Inoue and Nishio, 2004; Lu et al., 2009; Xu et al., 2009; Racchi et al., 2011; Swapna et al., 2011; Farhadian et al., 2012; Konovalov et al., 2012; Tantasawat et al., 2012). Many factors affect the sensitivity and resolution of SSCP analysis and include: 1) the type of mutation; 2) size of the DNA fragment and GC content; 3) composition and concentration of the gel; 4) gel temperature during electrophoresis; 5) molar ratio of the DNA to the primer; 6) composition of the electrophoresis buffer (including ionic strength and $\mathrm{pH}$ value); and 7) additives such as glycerol, sucrose, and formamide (Cai and Touitou, 1993; Chen et al., 1995; Teschauer et al., 1996; Kukita et al., 1997; Markoff et al., 1997; Paccoud et al., 1998; Gupta and Agarwal, 2003; Kakavas et al., 2006; Li et al., 2006; Zhu et al., 2006).

To simplify the experimental procedures of SSCP analysis, the unpurified PCR products are generally mixed with the loading buffer at a certain proportion before electrophoresis. However, since the residual primers after the PCR procedure will bind to ssDNAs by base pairing, both the bands from the ssDNA and those bound with the primers (pssDNA) are shown on a PAGE. The increased number of bands not only makes electrophoresis separation difficult, but it also lowers the effective numbers of both ssDNA and pssDNA molecules, therefore leading to weak-band patterns. Thus, it is difficult to obtain high-quality gel images (Almeida et al., 1998; Hennessy et al., 1998). Alfalfa (Medicago sativa) is an autotetraploid and naturally outcrossed; alfalfa cultivars comprise a heterogeneous synthetic population and are genetically complex, thus making genetic analysis for alfalfa difficult (Herrmann et al., 2010; Kumar, 2011). For example, for a single-gene locus, there may be 1-4 different alleles. Supposing that one allele corresponds to one DNA band in the SSCP images, one individual will have 2-8 bands. If the unpuri- 
fied PCR products are subject to electrophoresis, then 4-16 bands will appear. Therefore, many bands may be difficult to separate because of the close migration rates. Moreover, 2 groups of DNA bands from 2 complementary single strands may be mingled, thus decreasing the potential for differentiation. As a result, the band patterns are either impossible to interpret or likely to be misinterpreted.

When unpurified PCR products are mixed with sufficient amounts of primers for electrophoresis, only the bands corresponding to pssDNA will be shown on a PAGE. In most cases, the resultant PAGE patterns are consistent with those from ssDNAs only. The advantage of this method is that there is no need for purification of the PCR products. Moreover, the interference of residual primers on band patterns is removed. Since all ssDNA fragments bind with the primers, the intensity of the bands shown on a PAGE is greatly enhanced. Cai and Touitou (1993) studied the best ratio of purified PCR products to primers. Fregel et al. (2005) applied their method to the analysis of human ABO blood types and obtained good results. However, no research has been carried out on the mixing ratio of unpurified PCR products, primers, and loading buffer in autopolyploid species such as alfalfa. In addition, in the fluorescence-based PCR-SSCP technique (FPCRSSCP), 2 primers are labeled with different fluorescent dyes. Then, the 2 groups of bands from the 2 complementary single strands will be shown on 2 PAGE images. In this way, the difficulty of differentiating these 2 groups of bands in SSCP analysis is overcome. Therefore, the accuracy and reliability of the SSCP analysis for autopolyploid species is increased.

Polygalacturonase-inhibiting protein (PGIP) is considered a component of the defense system in plants and plays an important role in preventing fungi from infecting a plant (Di et al., 2006; Protsenko et al., 2008; Muthamilarasan and Prasad, 2013). However, there is little research, at present, on PGIP genes in alfalfa. In this study, the SSCP conditions of a fragment from the coding region of the MSPGIP2 gene, including the mixing ratio of the PCR products, primers, and loading buffer; crosslinking level (the mass ratio of Arc to Bis in PAGE); electrophoresis buffer; and use of fluorescent labeling, were optimized in order to identify the optimal conditions for SSCP analysis and provide assistance for the optimization of SSCP analysis for autopolyploid species.

\section{MATERIAL AND METHODS}

\section{Plant materials and DNA isolation}

The alfalfa variety 'Algonquin' was selected as the research material and its seed was provided by the Institute of Animal Sciences (IAS), Chinese Academy of Agricultural Sciences (CAAS). Forty 2-month-old individuals were sampled, and their genomic DNA was extracted from the young leaves using the cetyltrimethylammonium bromide (CTAB) method by Gao et al. (2013), with minor alterations (i.e., drying of the leaves by baking was replaced with liquid nitrogen freezing).

\section{PCR and preparation of electrophoresis samples}

The primers for $M S P G I P 2$ were designed according to the unpublished sequencing results of the authors in this study and a PGIP2 sequence (accession No. JF338623) from 
GenBank. The forward and reverse primers were 5'-ATCAGGCCCGATACCTTCTT-3', with a $\mathrm{Cy} 3$ of 5'-fluorescent label, and 5'-ACGAGCTCTTCTTAGGAACATC-3', with a 6 -FAM of fluorescent label, respectively. The PCR system had a total volume of $20 \mu \mathrm{L}$, with 20 ng genomic DNA, $0.2 \mu \mathrm{M}$ forward and reverse primers, $0.6 \mathrm{U}$ Taq DNA polymerase, 0.2 $\mathrm{mM}$ dNTPs, and $1.5 \mathrm{mM} \mathrm{MgCl}$. The PCR program was as follows: $94^{\circ} \mathrm{C}$ for $5 \mathrm{~min}$; followed by 35 cycles of $94^{\circ} \mathrm{C}$ for $30 \mathrm{~s}, 57^{\circ} \mathrm{C}$ for $45 \mathrm{~s}$, and $72^{\circ} \mathrm{C}$ for $1 \mathrm{~min}$; and an extension at $72^{\circ} \mathrm{C}$ for $8 \mathrm{~min}$ at the end. Then, the PCR products were mixed with the loading buffer [ $98 \%$ deionized formamide (v/v), $20 \mathrm{mM}$ EDTA, and $0.025 \%$ xylene cyanol FF (w/v)] and primers (unlabeled, $50 \mu \mathrm{M}$ forward and reverse primers) at a certain proportion (Figure 1). After denaturation for $10 \mathrm{~min}$ at $95^{\circ} \mathrm{C}$, the mixtures were quickly placed on ice, and $3 \mu \mathrm{L}$ was used for electrophoresis.

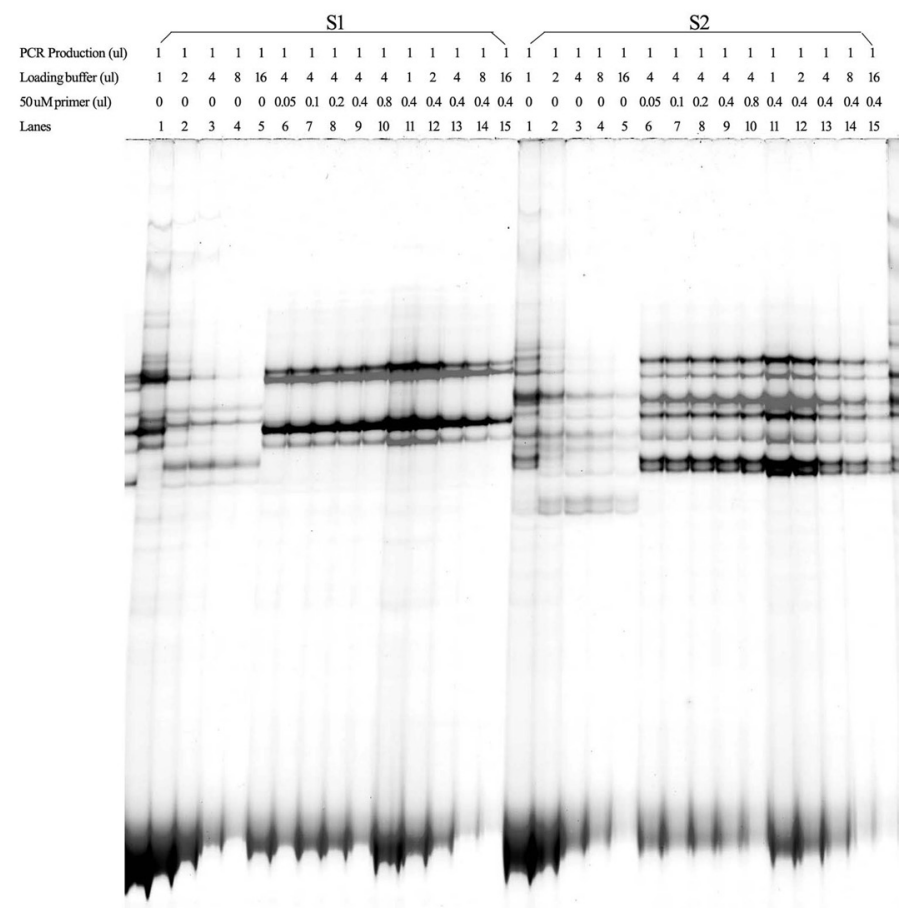

Figure 1. SSCP patterns for different mixing ratios of the PCR product, loading buffer, and unlabeled primer. S1 and S2, 2 plants of alfalfa. The electrophoresis buffer was 1X TBE, and the crosslinking level was 29:1.

\section{Electrophoresis}

The concentration of the polyacrylamide gel ( $45 \mathrm{~cm}$ x $35 \mathrm{~cm}$ x $0.4 \mathrm{~mm})$ was $8 \%$, with a 29:1 or 49:1 mass ratio of acrylamide:bisacrylamide. The electrophoresis buffers used were $0.5 \mathrm{X}$ TBE or $1 \mathrm{X} \mathrm{TBE}$, and the electrophoresis temperature was $5^{\circ} \mathrm{C}$. Electrophoresis was performed with a constant current for $1 \mathrm{~h}$ of pre-electrophoresis and $16 \mathrm{~h}$ of electrophoresis after loading. When the electrophoresis buffer was $0.5 \mathrm{X}$ TBE, the current was $7 \mathrm{~mA}$; when the electrophoresis buffer was $1 \mathrm{X}$ TBE, the current was $9 \mathrm{~mA}$. After electrophoresis, silver staining was performed (Bassam et al., 1991), and the gels were air-dried at room temperature and then 
photographed. If using fluorescent labeling primers, the gels were scanned with the TR1O+ Typhoon scanner (Amersham Biosciences, USA). The alleles and idiotypes were determined artificially. The alleles were successively designated by $a-z$ in increasing order of migration rate. Because alfalfa is an autotetraploid, when 2 or 3 alleles were found on a single-gene locus, the dose of the allele was determined based on the intensity of the bands in the FPCRSSCP images. In addition, after each electrophoresis, some of the samples were subjected to gel electrophoresis for a second time under the same conditions to verify the repeatability of the SSCP analysis.

\section{Sequencing}

To verify the reliability of our method, 9 plants were randomly selected from the alfalfa variety 'Algonquin', and all of their SSCP bands were sequenced. The target DNA bands

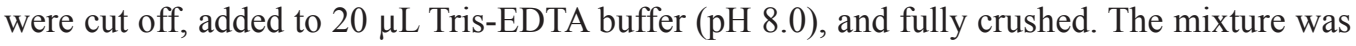
incubated at $65^{\circ} \mathrm{C}$ for $30 \mathrm{~min}$; then, the target DNA fragments were reamplified using $2 \mu \mathrm{L}$ of the mixture as a template. The PCR system and program were the same as those mentioned above. After purification of the reamplified product, the target DNA fragments were connected to pBS-T vectors and then transformed to Escherichia coli DH5a.3. The transformants carrying the target DNA fragments were randomly selected and sent to Shanghai Sangon Co. Ltd. for sequencing.

\section{RESULTS}

\section{Mixing ratio of PCR products, primers, and loading buffer}

The DNAs from 2 plants were used as PCR templates. A fragment of MsPGIP2 (331 bp) was subjected to PCR amplification (Figure 1). The results indicate that when the ratio of PCR product:loading buffer was 1:1 without the addition of the primer (Figure 1; lane 1), the bands of both the ssDNA and pssDNA appeared, but the latter had a higher band intensity than that of the former. When the ratio decreased from 1:2 to 1:8 (Figure 1; lanes 2, 3, and 4), the bands of both the ssDNA and pssDNA gradually weakened; however, the latter had a much quicker weakening speed than that of the former. When the ratio was 1:16 (Figure 1; lane 5), the bands of the pssDNA nearly disappeared, while the bands of the ssDNA were clearly visible but with weakened intensity. In addition, when the ratio was 1:1 or 1:2 (Figure 1; lanes 1 and 2), the nontarget bands could be clearly seen in the lane. This indicates that the bands of the pssDNA may completely disappear when the ratio of the PCR product:loading buffer was $\sim 1: 16$ without the addition of the primers. However, in this case, the samples with minimal amounts of the PCR products would generate bands too weak to be observed.

When the ratio of PCR products:loading buffer was fixed (1:4) and the addition amounts of the primers varied $(0.05,0.1,0.2,0.4$, and 0.8$), 4$ (plant 1) or 7 (plant 2) bands of the pssDNA were clearly observed for all treatments with consistent intensity (Figure 1; lanes $6,7,8,9$, and 10). However, when the addition amount of the primer was 0.05 for individual 1 , weak bands of the ssDNA appeared. This indicates that consistent and clear electrophoresis results could be obtained only when the addition amount of the primer was $>0.1$.

When the ratio of PCR products:primers (1:0.4) was fixed and the ratio of loading buffer varied $(1,2,4,8$, and 16), 4 (plant 1 ) or 7 (plant 2 ) bands from the pssDNA were clearly 
shown for all treatments, but the band intensity weakened with the increasing amounts of the loading buffer (Figure 1; lanes 11, 12, 13, 14, and 15). When the ratio of PCR products:loading buffer was 1:1 and 1:2 (Figure 1; lanes 11 and 12), the nontarget bands also appeared at the bottom of the lanes. It was thus indicated that only when the ratio of the PCR product:loading buffer was no more than 1:4 and a sufficient amount of the primer was added would clear band patterns be obtained.

\section{Crosslinking level and concentration of electrophoresis buffer}

When the volume ratio of PCR product:primer:loading buffer was 1:0.4:4, crosslinking levels and concentrations of the electrophoresis buffer varied in the SSCP analysis (Figure 2). The results showed that when the electrophoresis buffer was $0.5 \mathrm{X}$ TBE and the crosslinking level was 29:1, the numbers of bands for most plants were less than those in the other treatments, and the band patterns were notably different. This indicates that under such conditions, some alleles did not separate. In the other 3 treatments, the numbers of bands for all plants were the same, but the band patterns were different. Thus, under these conditions, different alleles were successfully separated but the migration rate differed. Among these 3 treatments, when the electrophoresis buffer was 0.5X TBE and the crosslinking level was 49:1, the band patterns were significantly different from those in the other 2 treatments and the distances between the bands were reduced, indicating that this treatment had low differentiation capability. When the electrophoresis buffer was $1 \mathrm{X}$ TBE and the crosslinking level was 29:1 and 49:1, separately, similar band patterns were produced. However, in the former treatment, the distance between the bands was large because this treatment (i.e., 1X TBE, crosslinking level 29:1) had a higher differentiation capability.
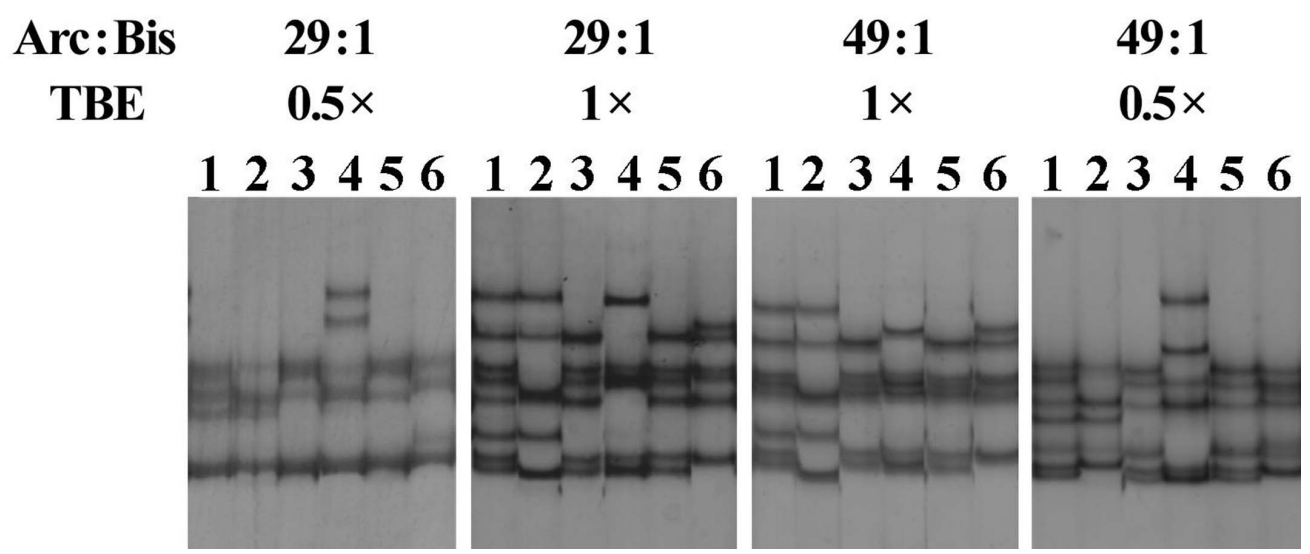

Figure 2. SSCP patterns for different crosslinking levels and concentrations of the electrophoresis buffer. Lanes 1-6, different plants of alfalfa; plant 3 and 6 shared the same genotypes.

\section{FPCR-SSCP analysis and sequencing}

Using the optimized conditions, FPCR-SSCP analysis was performed for 30 plants of the variety 'Algonquin' (Figure 3). The results showed that the 2 electrophoresis images from 2 complementary single strands were relatively clear, and most of the bands in these 2 images 
were distinguishable. On the first electrophoresis image (Figure 3; strand 1), 3 alleles (i.e., $c, d$ and $e$ ) showed small spaces that were difficult to differentiate. On the second electrophoresis image, 2 pairs of alleles (i.e., $d / i$ and $f / g$ ) were not completely separated (Figure 3; strand 2). However, by combining the 2 electrophoresis images, the alleles in each plant could be clearly determined. When the 2 electrophoresis images were superimposed, the 2 groups of bands from the 2 complementary single strands were mingled, making the determination of alleles and idiotypes difficult (Figure 3; strand $1+$ strand 2). Although the data could be obtained, the quality was poor.

In the PCR using fluorescent dyes, the fluorescence intensity was in direct proportion to the amount of the PCR product, and, thus, can be used to determine the dose of the alleles (Makino et al., 1992). After the gel-scanning parameters, image contrast and brightness were adjusted, the genotypes of all plants could be easily determined from the obtained images (Figure 3). For example, the genotypes of plants 2, 7, 8, 13, 17, 26, and 28 in Figure 3 were determined as $d f f h, c c d d, f h h h, b c d f, c c c c, c e h h$, and $c c c f$, respectively. In total, 9 alleles, $a-i$, were found among the 30 plants and their frequencies were 3.3, 0.8, 30.8, 8.3, 5.0, 23.3, 6.7, 20.8 , and $0.8 \%$, respectively. On the other hand, 24 genotypes were identified in 30 plants; the frequency of $c d f h$ was the greatest, with a value of $10 \%$. In addition, after electrophoresis of the PCR product for some plants on different gels under the same conditions, the same band patterns were obtained.

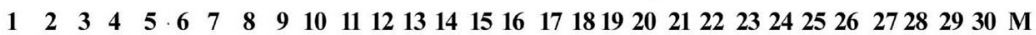

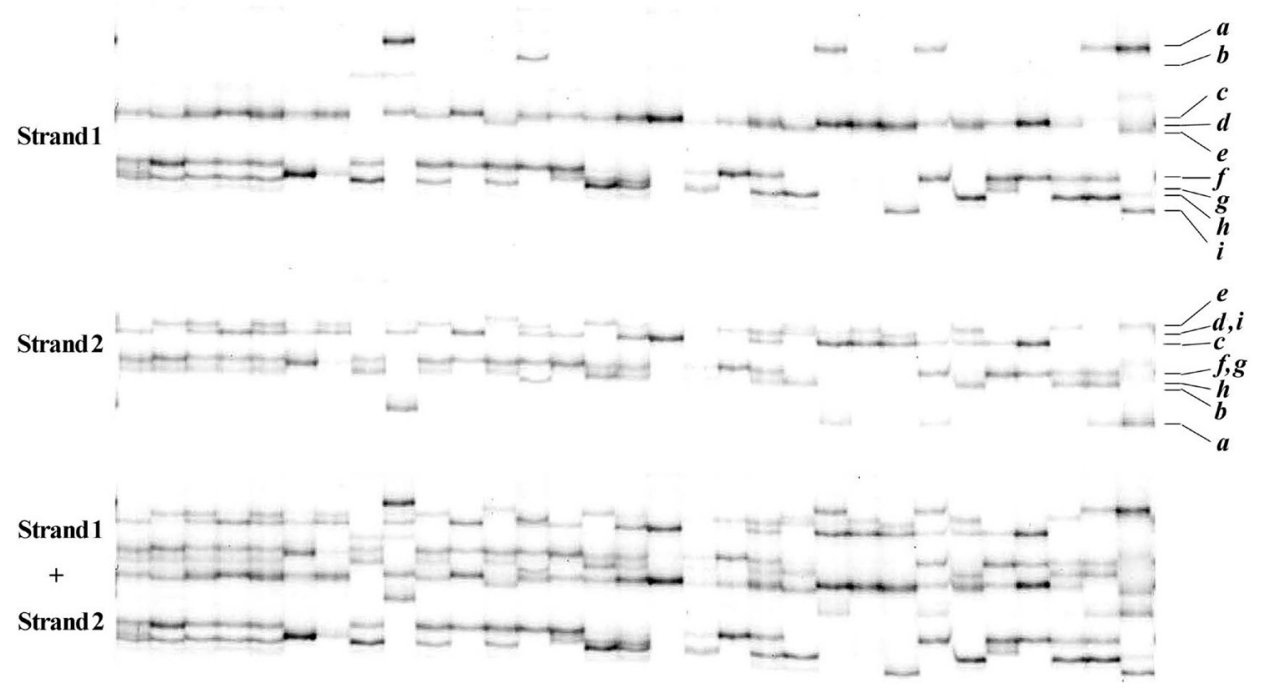

Figure 3. SSCP results of 30 plants of alfalfa variety 'Algonquin' when using a fluorescence-labeled primer and other optimized conditions. $a-i, 9$ different alleles; the electrophoresis buffer was $1 \mathrm{X}$ TBE, and the crosslinking level was 29:1.

The sequencing results suggest that most of the sequenced bands contained only one DNA fragment, the sequence of which varied with the bands. Figure 4 shows the sequences of alleles with a high allele frequency $(\geq 5 \%)$, and a total of 18 SNP sites were found with a tribase indel. Among the SNP sites found, 5 belonged to nonsynonymous replacements. 


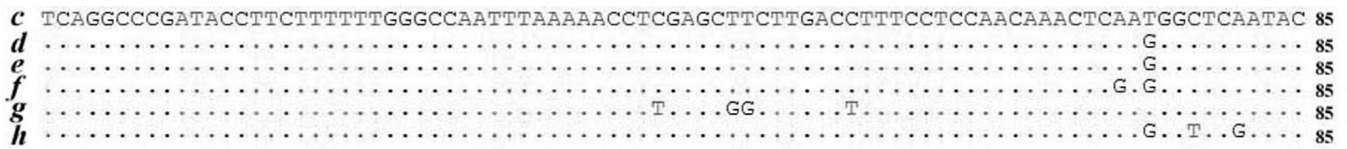

$\boldsymbol{c}$ CGAGTTCACTTTCCCAGTTGACCAACCTCAAACAATTATTCTTGCACGAGAACAAGCTTTCTGGACCCATTCCAGCTTCATTGGG 170

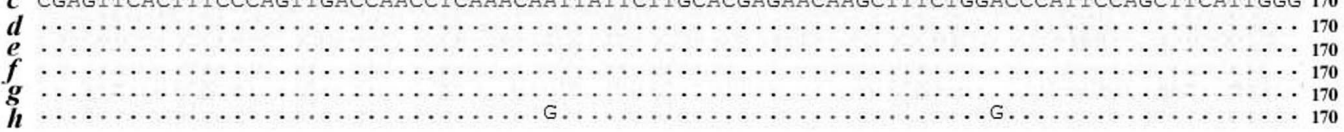

$c$ CCAACTAATTAATCTTGAGAGGTTAGCCTTGTCCAAGAACAGGCTTGTGGGTGATGCTTCCGTGCTTTTCGGGAGCAACAAAAGG 255

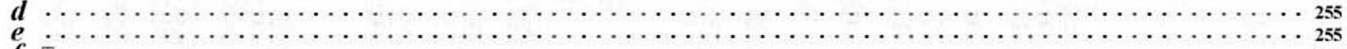

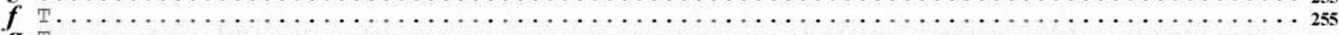

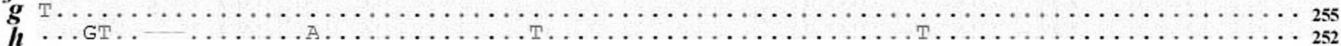

c ACAGAGTATATTGATCTTTCAAGGAACTTGTTTTCGTTTGATTTTTCAAAAGTTGATGTTCCTAAGAAGAGCTCGT

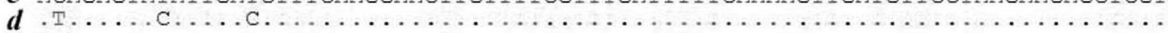

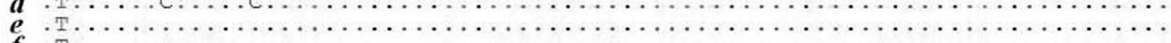

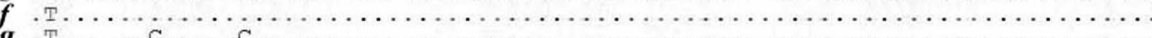

g

331

Figure 4. Variation in the DNA sequence of MsPGIP2 by SSCP analysis and sequencing. $c, d, e, f, g, h, 6$ alleles with frequencies $\geq 5 \%$.

\section{DISCUSSION}

The results in this study showed that when the loading mixture was made by mixing $1 \mu \mathrm{L}$ PCR products, 0.2 to $0.8 \mu \mathrm{L}$ unlabeled primers $(50 \mu \mathrm{M})$ and 4 to $16 \mu \mathrm{L}$ loading buffer, clear and consistent results of the SSCP analysis were obtained. The research by Cai and Touitou (1993) showed that the lowest concentration of primers in the PCR products affecting the SSCP band patterns was $0.006 \mu \mathrm{M}$. In this study, when the ratio of PCR product:loading buffer was 1:16 without the addition of the primer, the bands of the pssDNA completely disappeared. When the ratio was diluted to $1: 8$, the bands appeared. Thus, the ratio of $1: 12$ could be regarded as the lowest ratio at which the bands of the pssDNA disappeared. At this time, the concentration of the primer in the loading mixture approached $\sim 0.006 \mu \mathrm{M}$. Therefore, the concentration of the primers in the PCR product was $\sim 0.072 \mu \mathrm{M}$; then, the concentration of the target DNA fragment was $0.128 \mu \mathrm{M}$ (primer concentration $0.2 \mu \mathrm{M}$ in this study). When the volume ratio of PCR product:primer was 1:0.2, the residual primer in the loading mixture was 0.072 vs $10 \mathrm{pmol}$ of the added primers. The amount of the former could be neglected. Then, the molar ratio of the target DNA fragment:primer was 1:78. Zhu et al. (2006) found that when the molar ratio of the PCR product:primer was 1:100, the bands of the pssDNA nearly disappeared, which is consistent with the phenomenon observed in our study. Similar to Zhu et al. (2006), the results of our study further confirmed that the addition of the primer was simpler, more rapid, more sensitive, and less costly for SSCP analysis than purification of the PCR product.

Since the distance between 2 of the bands from some plants was extremely close, mixing occurred during the gel cutting operation. This led to the coexistence of 2 DNA fragments within only a few sequenced bands. However, the sequencing results from most of the bands were in perfect agreement with the data from the SSCP analysis. Combined with the good repeatability of the SSCP analysis in this study, this result shows that the determinations of the alleles and idiotypes were accurate in this study. Two studies have suggested that PGIP genes 
are highly conserved in Eucalyptus and Phaseolus vulgaris (Chimwamurombe et al., 2001; Farina et al., 2009). In contrast, in this study, more alleles with more SNP sites were found for $M S P G I P 2$. This indicates that $M S P G I P 2$ possesses greater sequence variation. The sequence variation found, particularly nonsynonymous replacement SNP sites, may be necessary for high-affinity recognition of divergent fungal polygalacturonases. Thus, further research on the association between $M S P G I P 2$ and the resistance of alfalfa to important fungal diseases could be easily performed based on the results in this study.

The results of this study show that the migration rate of the ssDNA was affected by the primer concentration in the SSCP analysis. With a comprehensive consideration of our results and the use of varied PCR system, it was determined that the loading mixture should be made by mixing the PCR products, the unlabeled primers $(50 \mu \mathrm{M})$ and the loading buffer at a ratio of 1:0.4:6; this should ensure the accuracy of the results of the SSCP analysis. In addition, for the PCR products in this study, the best SSCP patterns could be obtained when the electrophoresis buffer was $1 \mathrm{X}$ TBE and the crosslinking level was 29:1. Furthermore, FPCR-SSCP allowed the images of 2 single strands of DNA to be obtained separately, which made the determination of alleles and idiotypes more accurate and reliable. If the 4 different fluorescent dyes are used to label the 4 different primers, the PCR products from 2 DNA fragments could be simultaneously separated on a gel. This would double the efficiency of the analysis.

In conclusion, the SSCP analysis method developed in this study based on the addition of primers to PCR products in combination with the fluorescent labeling of primers could significantly improve the sensitivity and resolution of SSCP analysis, and the resultant molecular data would be more accurate and reliable. Thus, it could be used for genetic diversity detection and marker-assisted breeding of useful genes in autopolyploid species.

\section{ACKNOWLEDGMENTS}

Research kindly supported by the National Natural Science Foundation of China (\#31201840) and the National Science and Technology Project (\#2011BAD17B01).

\section{REFERENCES}

Almeida TA, Cabrera VM and Miranda JG (1998). Improved detection and characterization of mutations by primer addition in nonradioisotopic SSCP and direct PCR sequencing. Biotechniques 24: 220-221.

Bassam BJ, Caetano-Anollés G and Gresshoff PM (1991). Fast and sensitive silver staining of DNA in polyacrylamide gels. Anal. Biochem. 196: 80-83.

Cai QQ and Touitou I (1993). Excess PCR primers may dramatically affect SSCP efficiency. Nucleic Acids Res. 21: 3909-3910

Chen X, Baumstark T, Steger G and Riesner D (1995). High resolution SSCP by optimization of the temperature by transverse TGGE. Nucleic Acids Res. 23: 4524-4525.

Chimwamurombe PM, Botha AM, Wingfield MJ and Wingfield BD (2001). Molecular relatedness of the polygalacturonaseinhibiting protein genes in Eucalyptus species. Theor. Appl. Genet. 102: 645-650.

Di C, Zhang M, Xu S, Cheng T, et al. (2006). Role of poly-galacturonase inhibiting protein in plant defense. Crit. Rev. Microbiol. 32: 91-100.

Farhadian M, Hashemi A, Mardani K, Darvishzadeh R, et al. (2012). Polymorphisms in the ovine myostatin gene are associated with birth weight but not with weight gain in Iranian Makoei sheep. Genet. Mol. Res. 11: 3568-3575.

Farina A, Rocchi V, Janni M, Benedettelli S, et al. (2009). The bean polygalacturonase-inhibiting protein 2 (PvPGIP2) is highly conserved in common bean (Phaseolus vulgaris L.) germplasm and related species. Theor. Appl. Genet. 118: 1371-1379.

Fregel R, Maca-Meyer N, Cabrera VM, González AM, et al. (2005). Description of a simple multiplex PCR-SSCP method 
for $\mathrm{AB} 0$ genotyping and its application to the peopling of the Canary Islands. Immunogenetics 57: 572-578.

Gao JM, Xia BX, Luo F, Sun SJ, et al. (2013). Marker-assisted breeding for $r f 1$, a nuclear gene controlling A1 CMS in sorghum (Sorghum bicolor L. Moench). Euphytica 193: 383-390.

Gupta A and Agarwal S (2003). Efficiency and cost effectiveness: PAGE-SSCP versus MDE and Phast gels for the identification of unknown beta thalassaemia mutations. Mol. Pathol. 56: 237-239.

Hennessy LK, Teare J and Ko C (1998). PCR conditions and DNA denaturants affect reproducibility of single-strand conformation polymorphism patterns for BRCA1 mutations. Clin. Chem. 44: 879-882.

Herrmann D, Barre P, Santoni S and Julier B (2010). Association of a CONSTANS-LIKE gene to flowering and height in autotetraploid alfalfa. Theor. Appl. Genet. 121: 865-876.

Inoue H and Nishio T (2004). Efficiency of PCR-RF-SSCP marker production in Brassica oleracea using Brassica EST sequences. Euphytica 137: 233-242.

Ishikawa H, Watano Y, Kano K, Ito M, et al. (2002). Development of primer sets for PCR amplification of the PgiC gene in ferns. J. Plant Res. 115: 65-70.

Kakavas VJ, Noulas AV, Kanakis I, Bonanou S, et al. (2006). Identification of the most common cystic fibrosis transmembrane regulator gene DF508 mutation: evaluation of PCR-single strand conformational polymorphism and polyacrylamide gel electrophoresis. Biomed. Chromatogr. 20: 1120-1125.

Konovalov F, Shaturova A, Mitrofanova O and Kudryavtsev A (2012). An approach to DNA polymorphism screening in SBEIIa homeologous genes of polyploid wheat (Triticum L.). Euphytica 183: 173-184.

Kukita Y, Tahira T, Sommer SS and Hayashi K (1997). SSCP analysis of long DNA fragments in low pH gel. Hum. Mutat. 10: 400-407.

Kumar S (2011). Biotechnological advancements in alfalfa improvement. J. Appl. Genet. 52: 111-124.

Kusakabe T, Maekawa K, Ichikawa A, Uesugi M, et al. (1993). Conformation-selective DNA strand breaks by dynemicin: A molecular wedge into flexible regions of DNA. Biochemistry 32: 11669-11675.

Li W, Gao F, Tang W, Zhang X, et al. (2006). Detection of known thalassemia point mutations by snapback single-strand conformation polymorphism: the feasibility analysis. Clin. Biochem. 39: 833-842.

Lu YZ, Curtiss J, Percy RG, Hughs SE, et al. (2009). DNA polymorphisms of genes involved in fiber development in a selected set of cultivated tetraploid cotton. Crop Sci. 49: 1695-1704.

Makino R, Yazyu H, Kishimoto Y, Sekiya T, et al. (1992). F-SSCP: fluorescence-based polymerase chain reaction-singlestrand conformation polymorphism (PCR-SSCP) analysis. PCR Methods Appl. 2: 10-13.

Markoff A, Savov A, Vladimirov V, Bogdanova N, et al. (1997). Optimization of single-strand conformation polymorphism analysis in the presence of polyethylene glycol. Clin. Chem. 43: 30-33.

Muthamilarasan M and Prasad M (2013). Plant innate immunity: an updated insight into defense mechanism. J. Biosci. 38: 433-449.

Orita M, Iwahana H, Kanazawa H, Hayashi K, et al. (1989). Detection of polymorphisms of human DNA by gel electrophoresis as single-strand conformation polymorphisms. Proc. Natl. Acad. Sci. U S A 86: 2766-2770.

Paccoud B, Bourguignon J, Diarra-Mehrpour M, Martin JP, et al. (1998). Transverse formamide gradients as a simple and easy way to optimise DNA single-strand conformation polymorphism analysis. Nucleic Acids Res. 26: 2245-2246.

Protsenko MA, Buza NL, Krinitsyna AA, Bulantseva EA, et al. (2008). Polygalacturonase-inhibiting protein is a structural component of plant cell wall. Biochemistry 73: 1053-1062.

Racchi ML, Turchi A, Caparrini S and Camussi A (2011). SSCP intron marker system is a convenient tool for clonal fingerprinting of poplar (Populus) cultivars of different species and interspecific hybrids. Genet. Resour. Crop Evol. 58: 507-518.

Swapna M, Sivaraju K, Sharma RK, Singh NK, et al. (2011). Single-strand conformational polymorphism of EST-SSRs: a potential tool for diversity analysis and varietal identification in sugarcane. Plant Mol. Bio. Rep. 29: 505-513.

Tantasawat PA, Poolsawat O, Prajongjai T, Chaowiset W, et al. (2012). Association of RGA-SSCP markers with resistance to downy mildew and anthracnose in grapevines. Genet. Mol. Res. 11: 1799-1809.

Teschauer W, Mussack T, Braun A, Waldner H, et al. (1996). Conditions for single strand conformation polymorphism (SSCP) analysis with broad applicability: a study of the effects of acrylamide, buffer and glycerol concentrations in SSCP analysis of exons of the $p 53$ gene. Eur. J. Clin. Chem. Clin. Biochem. 34: 125-131.

Xu X, Babu R, Fujimura T and Kawasaki S (2009). A high-throughput, low cost gel-based SNP assay for positional cloning and marker assisted breeding of useful genes in cereals. Plant Breed. 128: 325-331.

Zhu X, Niu N, Liu Y, Du T, et al. (2006). Improvement of the sensitivity and resolution of PCR-SSCP analysis with optimized primer concentrations in PCR products. J. Genet. 85: 233-235. 